\title{
EFFECT OF PVA MODIFICATION ON THE PROPERTIES OF CEMENT COMPOSITES
}

\author{
JaroslaV TopiČ ${ }^{a, *}$, ZdeněK ProšEK ${ }^{a}$, Kateřina Indrováa $^{a, b}$, \\ Tomáš PlachÝ ${ }^{a}$, VÁclav NeŽerka ${ }^{a}$, Lubomír KopeckÝ ${ }^{a}$, Pavel TesáreK ${ }^{a}$ \\ ${ }^{a}$ Faculty of Civil Engineering, Czech Technical University in Prague, Thákurova 7, 166 27 Prague, Czech \\ Republic \\ ${ }^{b}$ Faculty of Biomedical Engineering, Czech Technical University in Prague, Náměstí Sítná 3105, 27201 Kladno, \\ Czech Republic \\ * corresponding author: jaroslav.topic@fsv.cvut.cz
}

\begin{abstract}
Polymers have been used for modifying cement-based composites and other building materials since the 1930s. Recent studies have assumed that even water soluble polymers can be used as an admixture for a modification of this kind. Several ways for modifying mortars, wood-based products and bituminous asphalts with a polymer are known and are currently being exploited. Various options differ in the way in which the modification is made. It can be applied basically to the entire volume or just to a surface, and the polymer can be used in the form either of a solution or of fibers. The aim of our study was to investigate the influence of modifying the volume with water soluble polymers, such as polyvinyl alcohol (PVA), on the properties of a cement paste, and to find an optimal additive. It turned out that the addition of a PVA solution into fresh cement paste increases the porosity and therefore reduces the stiffness and the compressive strength. However, the bending strength of PVA-rich specimens was significantly higher and their water absorption decreased, which may result in enhanced frost resistance.
\end{abstract}

KEYWORDS: cement modification; polymer; PVA; bending strength; water absorption; mechanical properties.

\section{INTRODUCTION}

The use of polymers for modifying cement-based composites is currently very widespread, because polymers improve the properties of the material, e.g., compressive strength and bending strength. In early studies, natural latex was used. Other polymers gradually came into use, such as polyvinyl acetate, styrene butadiene, polyacrylic ester and polyester resin. Significant improvements were achieved with the use of these polymers, but they are in massive use in present-day construction, and price has become a major issue for these polymers. Thanks to its lower cost, PVA could be suitable for replacing widely-used polymers. The outcomes of our study will help to outline future opportunities for using PVA in cement composites. This composite has low water absorption, and it is assumed that it can be used especially for structures exposed to water and frost cycles.

One of the ways to use PVA for modifying cement composites is in the form of a water solution [1, 2]. Knapen et al. [3, 4] conducted a study in which PVAA (polyvinyl alcohol-acetate) was used for modifying a cement paste and mortar. In these studies, they tested the influence of water on the composite, the basic mechanical properties and changes in the hydration process. They observed changes leading to retardation of the hydration process and a decrease in the $\mathrm{Ca}(\mathrm{OH})_{2}$ content in the presence of PVAA. They also found polymer bridges between layered $\mathrm{Ca}(\mathrm{OH})_{2}$ crystals acting as a bonding agent. Together with better internal cohesion, these factors probably led to lower crack formation and better flexural end splitting tensile strength of the PVAA-enriched cement composites. However, these composites were sensitive to moisture and to the presence of water, leading to deteriorated mechanical properties.

A study by Viswanath [5] proved that the presence of $2 \%$ PVAL (a mixture of PVA and phenol formaldehyde) improves the acid resistance of Portland cement pastes, although its strength parameters remain comparable to those of a pure cement paste. These properties, especially compressive strength, are improved by adding traces of borax into the compound. Pique et al. [6] used $4 \mathrm{wt} \%$ PVA in their study of the changes in the hydration process of a modified cement paste. Like Knapen et al. 4, they detected retardation in the hydration process of a cement paste modified by PVA. Pique et al. also observed an increase in the flexural strength, caused by the formation of a PVA film around the growing hydration products during setting and hardening. They came to the conclusion that the decrease in compressive strength was caused by higher porosity of the modified cement paste. Morlat et al. [7] conducted a study in which they used a mixture of cement and PVA as a high-molecular mass polymer, and examined the mechanical properties of the cement paste that was produced. They detected 


\begin{tabular}{lcc}
\hline Content & {$[\%]$} & \multicolumn{1}{c}{ Method } \\
\hline $\mathrm{CaO}$ & 66 & EN 196-2, XRF \\
$\mathrm{SiO}_{2}$ & 20 & EN 196-2, XRF \\
$\mathrm{AL}_{2} \mathrm{O}_{3}$ & 4 & EN 196-2, XRF \\
$\mathrm{Fe}_{2} \mathrm{O}_{3}$ & 3 & EN 196-2, XRF \\
$\mathrm{MgO}_{\mathrm{SO}_{3}}$ & 2 & EN 196-2, XRF \\
$\mathrm{S}^{\mathrm{II}}$ & 3 & EN 196-2, XRF \\
$\mathrm{Cl}^{-}$ & 0.05 & EN 196-2 \\
$\mathrm{K}_{2} \mathrm{O}$ & 0.052 & EN 196-2, XRF \\
$\mathrm{Na}_{2} \mathrm{O}$ & 0.76 & EN 196-2, XRF \\
\hline
\end{tabular}

TABle 1. Chemical properties of the Portland cement CEM I 42.5 R used in the experiments.

an increase in flexural strength, and the fracture energy increased by a factor of three when less than $4 \mathrm{wt} \%$ PVA with respect to cement was added. They also explained these results, claiming that nodules of PVA induce better control of the fracture process, specifically during crack propagation. These results were achieved despite an increase in porosity.

Different results, indicating an increase in compressive strength and a reduction in porosity in cement and PVA compounds were reported by Singh and Rai [8]. They concluded that PVA and cement form a special chemical interaction, and its product fills the pores and voids. Yongjia et al. [9 concluded that adding PVA into a cement paste can alter the morphology of the Si-O chains, and can therefore reduce the porosity. Kim et al. [10, 11] conducted a more detailed study examining the processes within the structure of PVA and mortar. The air void contents were increased, leading to a reduction in the density of the compound after adding up to $2 \mathrm{wt} \%$ PVA. The porous interfacial transition zones around the sand grains and the coarse aggregates were significantly reduced in size and in quantity, and the unhydrated cement particles were distributed more uniformly in the cement matrix, without significant depletion near the surfaces of the aggregate.

A study by Mojumdar and Raki [12] suggests that a nanocomposite of cement and PVA could be developed for future application in the construction field, e.g., for coatings with corrosion protection and fire resistance. Kou et al. 13 explored RCA (Recycled Concrete Aggregate) as a plausibly appropriate structural concrete after impregnation with PVA. According to their study, the optimal concentration of PVA solution is $10 \%$ for a sufficient reduction of water absorption together with better mechanical properties than untreated RCA.

The possibility of PVA reinforcement of cement composites in the form of fibers was investigated by Shaikh and Hirozo 14, who conducted a study on the strain hardening behavior of lightweight PVA fiberreinforced cement composites. The results show that a composite containing $2 \%$ of PVA fibers $12 \mathrm{~mm}$ in

\begin{tabular}{lcl}
\hline Content & {$[\%]$} & Method \\
\hline Clinker & 90 & \\
$\mathrm{MgO}$ & 2.0 & $\mathrm{XRF}$ \\
$\mathrm{C}_{3} \mathrm{~S}$ & 73 & $\mathrm{XRF}$ \\
$\mathrm{C}_{2} \mathrm{~S}$ & 6 & $\mathrm{XRF}$ \\
$\mathrm{C}_{3} \mathrm{~A}$ & 9 & $\mathrm{XRF}$ \\
$\mathrm{C}_{4} \mathrm{AF}$ & 9 & $\mathrm{XRF}$ \\
\hline
\end{tabular}

TABle 2. Composition of the cement and clinker of the Portland cement CEM I 42.5 R.

length and $1 \%$ of thinner PVA fibers $6 \mathrm{~mm}$ in length showed the best performance in terms of ultimate strength, crack opening displacement and smeared cracking development, and composites containing fine lightweight aggregates exhibited the greatest strength. The mechanical properties of cement-based composites reinforced by PVA fibers were also examined by Shilang and Shuling [15, who claim that a composite of this kind has 70 times greater tensile strength than plain concrete. Noushini et al. 16 presented a study on the dynamic properties of concrete reinforced with PVA fibers, and concluded that the reinforcement has no significant effect on damping the dynamic loading.

Lhoneux et al. [18] performed a long-term study of the behavior of a PVA-cement composite under various weather conditions, exposing the fiber-cement specimens to mild climate conditions and studying the hygrothermal properties. The study showed that fibers do not degrade substantially when exposed to natural weathering, and PVA fiber-cement products can be considered durable. Another study examining the effects of temperature on the tensile behavior and strain hardening in cement-based composites was conducted by Mechtcherine et al. [19]. They demonstrated that the tensile strength decreases both with an increase in temperature and with a decrease in the strain rate.

\section{EXPERIMENTAL MATERIALS AND TESTED SAMPLES}

The samples were made of Portland cement CEM I 42.5 R, produced in Radotín by Českomoravský Cement, Ltd. The chemical composition is presented in Tables 1 and 22 PVA, made by alkaline hydrolysis of polyvinyl acetate in methanol (brand name SLOVIOL® R), produced by Fortischem, Ltd., was added into the cement in the form of a solution of concentration equal to $16 \pm 1.5 \%$, with an $80 \%$ degree of hydrolysis and molar mass ranging between 60000 and $80000 \mathrm{~g} / \mathrm{mol}$.

A reference set of samples, denoted AS, was made of cement and water without any addition of PVA. Other sets, denoted as BS, CS, DS and ES, differ in the amount of PVA in the mixture (Table 3). All mixtures were made with a water and PVA solution to cement ratio equal to 0.35 . Therefore, the PVA solution 


\begin{tabular}{ccrcc}
\hline Set & Cement & Water & $\begin{array}{c}\text { PVA } \\
\text { solution } \\
{[\mathrm{g}]}\end{array}$ & $\begin{array}{c}\text { PVA } \\
{[\text { wt\% of }} \\
\text { cement] }\end{array}$ \\
\hline AS & 1000 & 350.0 & 0.0 & 0.0 \\
BS & 1000 & 232.5 & 87.5 & 1.4 \\
CS & 1000 & 175.0 & 175.0 & 2.8 \\
DS & 1000 & 100.0 & 250.0 & 4.0 \\
ES & 1000 & 0.0 & 350.0 & 5.6 \\
\hline
\end{tabular}

TABLE 3. Composition of the cement-PVA samples $(\mathrm{w} / \mathrm{c}=0.35)$.

partly (BS to DS) or completely (ES) substituted mixing water.

Water and PVA were mixed in proportions that would achieve the desired PVA content while keeping the water-to-cement ratio ( $\mathrm{w} / \mathrm{c}$ ) equal to 0.35 . Then the cement was added and a homogeneous mixture was prepared by manual mixing. The prepared mixture was placed into casts and was compacted for 3 minutes. The samples were removed from the casts after 2 days of hardening and were cured for the next 26 days in laboratory conditions at a temperature of $21 \pm 2{ }^{\circ} \mathrm{Cand}$ relative humidity equal to $50 \pm 5 \%$.

The specimens with dimensions of $40 \times 40 \times 160 \mathrm{~mm}$ were used mainly for non-destructive testing, while the $20 \times 20 \times 100 \mathrm{~mm}$ AS to ES specimens were intended for destructive testing. Each set representing a specific PVA content was composed of 6 samples. The specimens intended for a microstructure examination by optical and scanning electron microscopy were cylindrical in shape and were $30 \mathrm{~mm}$ in diameter and $50 \mathrm{~mm}$ in height. These specimens were cut into slices $5 \mathrm{~mm}$ in thickness using a diamond saw, and were polished with silicon carbide grinding papers down to \#4000 grit. Technical alcohol was used for cleaning the specimens in an ultrasonic bath between the individual polishing steps.

\section{EXPERIMENTAL METHODS}

The consistency of the fresh pastes was determined using the standard flow expansion test [20], and the setting time was measured using Vicat apparatus on two representative samples for each set every $10 \mathrm{~min}$ utes after they were prepared. When the distance between the tip of the Vicat needle and the table was $6 \pm 3 \mathrm{~mm}$, the initial setting time was reached. Setting was considered to have ended when the tip of the needle penetrated only $0.5 \mathrm{~mm}$ into the cement paste [21].

The hydration heat measurements were conducted on an isothermal TAM Air calorimeter for accurate measurements of the heat flow and the hydration heat production. Eight chambers were used for the measurements and the mixtures were tested continuously for 7 days at a constant temperature of $20^{\circ} \mathrm{C}$. The mixtures were in sealable plastic containers, each containing from 9 to $16 \mathrm{~g}$ of the mixture. The results for heat flow and hydration heat were related to $1 \mathrm{~g}$ of the cement according to their total weight 22 .

The microstructure and the structure of the voids were examined using optical and scanning electron microscopy (SEM). A NEOPHOT 21 optical metallurgical microscope was used to obtain images at low magnification $(80 \times)$. A Philips XL30 ESEM-TMP FEI scanning electron microscope was used to provide information about the structure of the pores and for identifying the individual phases at $100 \times$ magnification. SEM images at $500 \times$ magnification enabled us to investigate the changes in the microstructure of the modified cement paste. SEM was used in the BSE mode at low pressure (10-20 Pa) and at accelerating voltage set to $30 \mathrm{kV}$. The quality of the surface was checked using an atomic force microscope (DME 2329 Dual Scope ${ }^{\mathrm{TM}}$ Probe Scanner DS 95-200) to obtain undistorted high-quality SEM images.

The water absorption testing and the measurements of the residual water content were carried out on the prismatic $40 \times 40 \times 160 \mathrm{~mm}$ specimens after 34 days of curing. The water absorption was determined according to following equation after keeping the samples submerged in water for 2 hours and for 24 hours:

$$
n_{\mathrm{h}}=\frac{m_{\mathrm{n}}-m_{\mathrm{s} 1}}{m_{\mathrm{s} 1}} \cdot 100 \%,
$$

where $m_{\mathrm{n}}$ is the weight of a soaked sample and $m_{\mathrm{s} 1}$ is the weight of a dry sample.

The residual water content was determined on the dried samples after keeping them for 24 hours at a temperature of $21 \pm 2{ }^{\circ} \mathrm{Cand}$ at relative humidity of $50 \pm 5 \%$, as follows:

$$
v_{\mathrm{h}}=\frac{m_{\mathrm{s} 2}-m_{\mathrm{s} 1}}{m_{\mathrm{n}}-m_{\mathrm{s} 1}} \cdot 100 \%,
$$

where $m_{\mathrm{n}}$ is the weight of a soaked (after 2 hours) sample, $m_{\mathrm{s} 1}$ is the weight of a dry sample, and $m_{\mathrm{s} 2}$ is the weight of a sample after 24 hours of naturally drying.

The dynamic Young's modulus and shear modulus were monitored using the resonance method, based on measurements of the natural frequency measured on the prismatic $40 \times 40 \times 160 \mathrm{~mm}$ samples, every 7 days for a period of 42 days. The measurements were made on 6 samples for each set, and the last measurement was made after 161 days of hardening. The resonance detection was performed using the Brüel \& Kjaer assembly, consisting of a measurement station type 3560-B-120, recording the excitation and response signals, type 4519-003 acceleration transducers, an 8206 impact hammer type and a computer. The method requires knowledge of the dimensions and the weight of each sample prior to testing.

The response signals were transformed from the time domain to the frequency domain using the Fast Fourier Transform. The Frequency Response Function (FRF) was calculated as the ratio of the response and the excitation force in the frequency domain. The 


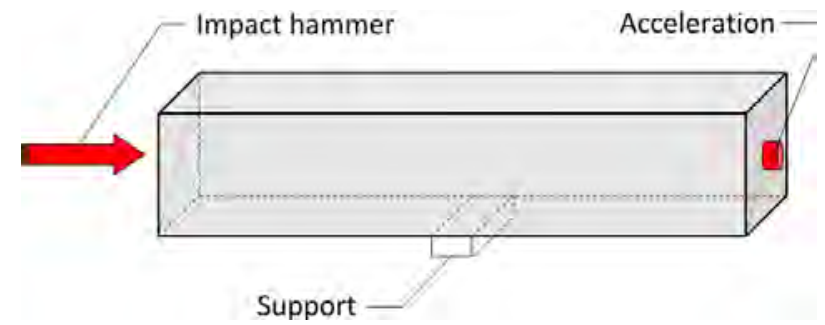

Figure 1. The basic resonance frequency excitation of longitudinal vibration by the impact resonance method.

appropriate basic natural frequencies were evaluated from the FRFs. Then the dynamic Young's modulus and shear modulus were evaluated using the following method.

The dynamic Young's modulus was evaluated based on the basic longitudinal natural frequency of the samples (Figure 1):

$$
E_{d, l}=\frac{4 l m f_{1}^{2}}{b t}
$$

where $E_{d, l}$ is the dynamic Young's modulus [Pa], $l$ is the length of the sample $[\mathrm{m}], m$ is the mass of the sample $[\mathrm{kg}], f_{1}$ is the basic longitudinal natural frequency of the sample $[\mathrm{Hz}], b$ is the thickness of the sample $[\mathrm{m}]$, and $t$ is the height of the sample $[\mathrm{m}]$.

The basic flexural natural frequency (Figure 2) was used to verify the longitudinal measurements. The errors between measurements were less than $2 \%$, so results presented later were obtained only from the longitudinal frequency. In this case, the dynamic Young's modulus was evaluated using

$$
E_{d, p}=\frac{0.9465 l^{3} m f_{\mathrm{p}}^{2} T_{1}}{b t^{3}}
$$

where $E_{d, p}$ is the dynamic Young's modulus [Pa], $l$ is the length of the sample $[\mathrm{m}], m$ is the mass of the sample $[\mathrm{kg}], f_{\mathrm{p}}$ is the basic flexural natural frequency of the sample [Hz], $T_{1}$ is the correction factor to account for the finite thickness of the sample and the Poisson's ratio (defined by ASTM 1876-01 (2006) [27), $b$ is the thickness of the sample $[\mathrm{m}]$, and $t$ is the height of the sample $[\mathrm{m}]$.

The dynamic shear modulus was evaluated from the basic torsional natural frequency of the sample (Figure 3), using following the formulas:

$$
\begin{gathered}
G_{\mathrm{d}}=\frac{4 l m f_{\mathrm{t}}^{2}}{b t} \frac{B}{1+A}, \\
B=\frac{b / t+t / b}{4 t / b-2.52(b / t)^{2}+0.21(t / b)^{6}},
\end{gathered}
$$

where $G_{\mathrm{d}}$ is the dynamic shear modulus $[\mathrm{Pa}], l$ is the length of the sample $[\mathrm{m}], m$ is the mass of the sample $[\mathrm{kg}], f_{\mathrm{t}}$ is the basic torsional natural frequency of the sample $[\mathrm{Hz}], b$ is the thickness of the sample $[\mathrm{m}], t$ is the height of the sample [m], and $A$ is the

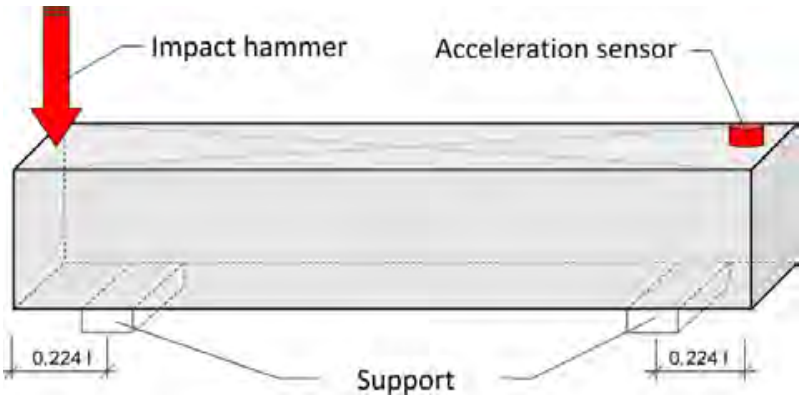

FIGURE 2. The basic resonance frequency excitation of flexural vibration by the impact resonance method.

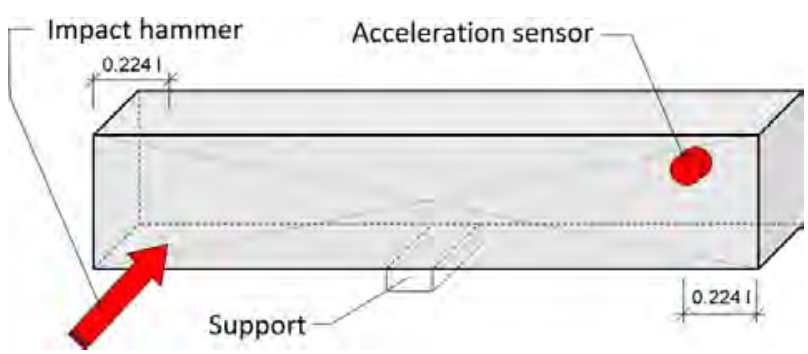

Figure 3. The basic resonance frequency excitation of torsional vibration by the impact resonance method.

empirical correction factor depending on the widthto-thickness ratio of the sample (defined by ASTM 1876-01 (2006) [27]).

The samples were supported by a soft elastic pad at the nodal points of the 1st naural mode shape of longitudinal (Figure 1), flexural (Figure 2) and torsional (Figure3) vibration [26-29]. A benefit of this kind of measurement is that the dynamic Young's modulus can be monitored over an extended period 6 .

The flexural and compressive strength were determined on the 28-day-old samples using the LabTest 4.100SP1 device. The testing was displacement controlled at a constant rate of $0.1 \mathrm{~mm} / \mathrm{s}$ (bending) and $0.3 \mathrm{~mm} / \mathrm{s}$ (compression). A three-point bending test was performed on the prismatic $20 \times 20 \times 100 \mathrm{~mm}$ specimens, and a uniaxial compression test was then performed on the broken specimens with effective dimensions of $20 \times 20 \times 40 \mathrm{~mm}$. Each set contained 12 samples. The results should supplement the data already published [6, 8, 11] with a systematic study on the effect of a different PVA concentration in the tested cement pastes 31.

The static Young's modulus was determined from the uniaxial compressive test, but the results are influenced by the compliance of the testing frame. The results provided by dynamic testing are therefore considered more relevant, while the static measurement was used only for comparing the individual samples [32].

\section{EXPERIMENTAL RESUlts}

The flow test results summarized in Table 4 show a clear reduction in the workability of mixtures containing PVA. There is clearly inverse proportionality of the PVA content to the workability of the fresh pastes. 


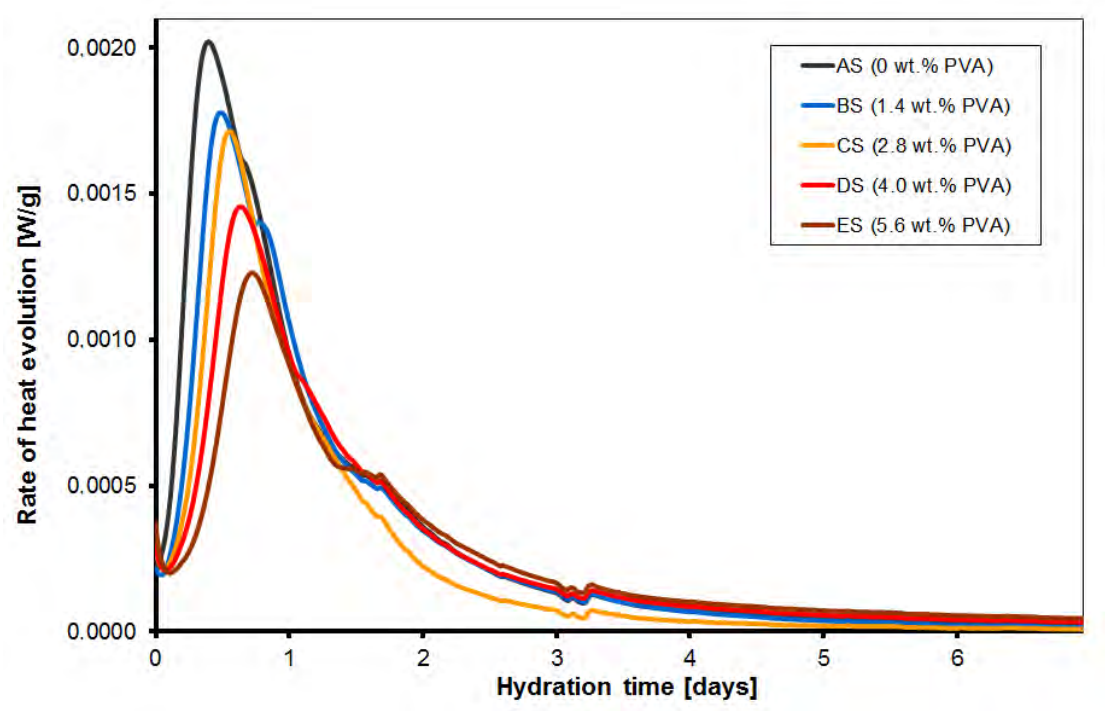

Figure 4. Rate of the heat evolution at $20^{\circ} \mathrm{C}$ for the reference (AS) and PVA-modified (BS-ES) cement pastes with $\mathrm{w} / \mathrm{c}=0.35$.

\begin{tabular}{lccc}
\hline Set & $\begin{array}{c}\text { Flow test } \\
\text { expansion } \\
{[\mathrm{mm}]}\end{array}$ & $\begin{array}{c}\text { Initial } \\
\text { setting } \\
{[\mathrm{min}]}\end{array}$ & $\begin{array}{c}\text { End of } \\
\text { setting } \\
{[\mathrm{mm}]}\end{array}$ \\
\hline AS (0 wt\% PVA) & 150 & 290 & 380 \\
BS (1.4 wt\% PVA) & 140 & 340 & 450 \\
CS (2.8 wt\% PVA) & 120 & 365 & 470 \\
DS (4.0 wt\% PVA) & 100 & 375 & 490 \\
ES (5.6 wt\% PVA) & 90 & 225 & 360 \\
\hline
\end{tabular}

TABLE 4. Results of the flow expansion test and the setting times of cement pastes modified by PVA.

For the ES mixtures, the mixture maintained more or less the originshape after the mold was removed. In addition, the higher adhesion viscosity of the PVAenriched samples made mixing and pouring into the molds problematic.

The PVA content in the mixture influences the hydration process by delaying the initial and end setting times with respect to the reference cement paste (AS), see Table 4 For the most concentrated DS mixture, the initial setting time was delayed by about 85 minutes, and the setting process lasted about 25 minutes longer than for the reference sample. The setting time could not be properly determined for the ES samples, due to the high viscosity. The Vicat needle did not pass through the mixture to the bottom immediately after the mixture was placed in the mold. It is therefore necessary to use a different method to determine the setting times accurately for very rich PVA samples.

The heat flow monitored on all tested samples during the initial 7 days of setting and hardening is shown in Figure 4 The location and the size of the heat flow peak depend on the amount of PVA. In the reference mixture, the maximum heat flow value $0.002021 \mathrm{~W} / \mathrm{g}$ for the cement was reached after approximately 9 hours. For the BS to ES mixtures, the maximum heat flow decreases with the increasing amount of PVA, and shifts further in time. In the case of the ES mixture, the maximum heat flow achieved a value equal to $0.001229 \mathrm{~W} / \mathrm{g}$ after 17 hours, which is a reduction by $40 \%$ delayed by about 8 hours compared to the reference mixture. However, mixtures DS and ES exhibit slightly higher heat generation in the later stages of hardening from 2 to 7 days. The ES sample generated total hydration heat in an amount about $28 \%$ lower than for the reference cement paste. We assume that the unusual bump around the 3rd day may have been due to restored hydration of unhydrated $\mathrm{C}_{3} \mathrm{~A}$ producing ettringite [1]. In this case, the effect could have been magnified by violation of the PVA barrier around the cement grains and increased diffusion of water to $\mathrm{C}_{3} \mathrm{~A}$. However, this is only a hypothesis that needs to be verified.

It is obvious from Table 5 that the addition of PVA increased the porosity and reduced the bulk density. Samples poor in PVA (BS) had bulk density about $16 \%$ lower than for the reference (AS) set, and the bulk density of the PVA-rich (ES) samples was about $26 \%$ lower. The increase in porosity with the addition of PVA is also apparent from the microscopy images.

The optical and electron microscopy analyses clearly demonstrate the changes in the pore structure of the samples modified by PVA. The presence of technological spherical pores from 30 to $300 \mu \mathrm{m}$ in diameter in the PVA modified pastes is obvious from the optical microscopy images taken at $80 \times$ magnification (Figures 6 and 7). The reference sample without PVA contained almost no visible pores. There is also an apparent increase in the number of pores spanning all diameters with the addition of PVA, with the exception of pores larger than $200 \mu \mathrm{m}$, which are absent in the BS samples. Samples CS and DS contain a rela- 

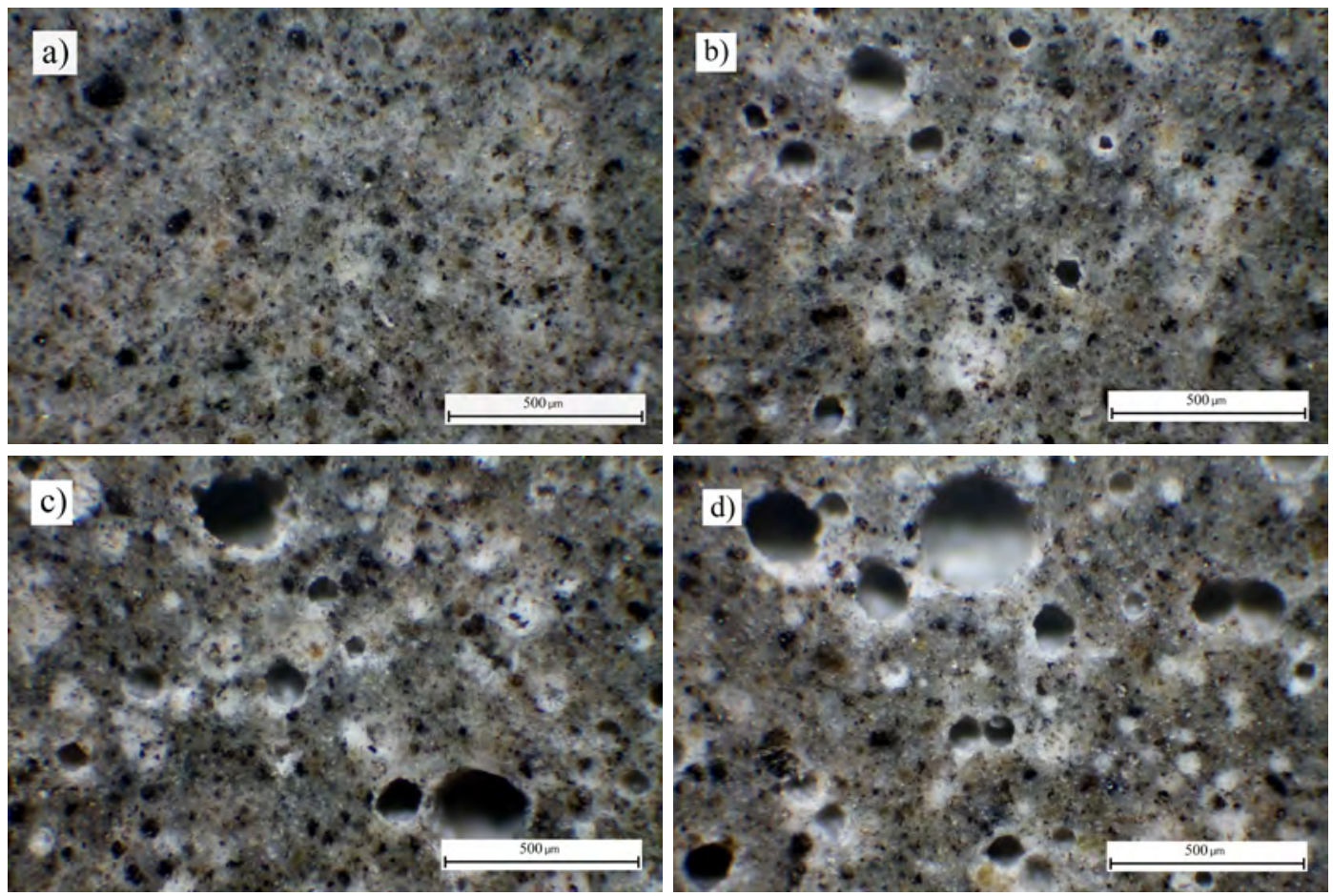

Figure 6. Optical microscopy images of the cement pastes with $\mathrm{w} / \mathrm{c}=0.35$ modified by PVA at $80 \times$ magnification: a) AS sample (0 wt\% PVA), b) BS sample (1.4 wt\% PVA), c) CS sample (2.8 wt\% PVA), d) DS sample (4.0 wt\% PVA).

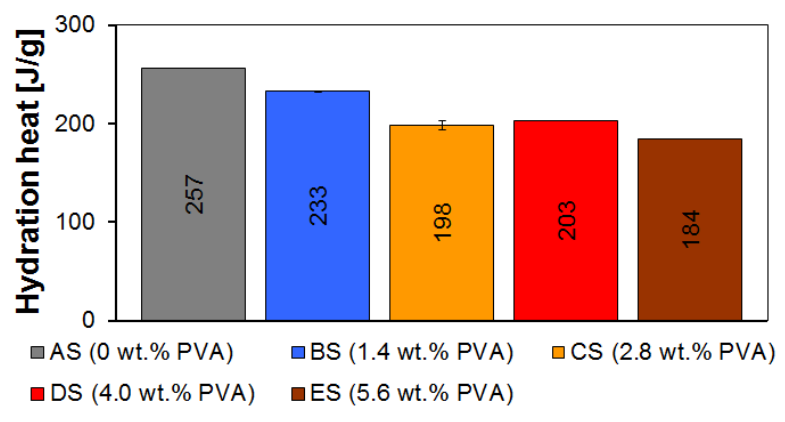

FiguRE 5. Hydration heat (for 7 days) of the cement pastes with $\mathrm{w} / \mathrm{c}=0.35$ related to the PVA content.

tively large number of pores about $300 \mu \mathrm{m}$ in diameter, and a substantial number of pores had a pore size of about $60 \mu \mathrm{m}$. The DS samples also contained a limited number of pores about $500 \mu \mathrm{m}$ in diameter.

The distribution of the various phases within the cement paste can be detected in the SEM images. On the basis of the images at $100 \times$ and $500 \times$ magnifications, the unhydrated cement grains (displayed as white spots) can be clearly identified. The light gray spots are formed mainly by $\mathrm{Ca}(\mathrm{OH})_{2}$ (portlandite), the dark gray areas represent hydrates (mainly C-S-H gels), and the black areas represent air voids. The increase in porosity related to the increasing amount of PVA is in agreement with the results of the bulk density and total porosity measurements, which are summarized in Table 5 . The presence of small pores $(10 \mu \mathrm{m})$ for samples containing PVA is visible in the SEM images at $500 \times$ magnification. When comparing these sets, the presence of individual phases is

\begin{tabular}{llc}
\hline Set & $\begin{array}{c}\text { Bulk density } \\
{\left[\mathrm{kg} / \mathrm{m}^{3}\right]}\end{array}$ & $\begin{array}{c}\text { Total } \\
\text { porosity }[\%]\end{array}$ \\
\hline AS (0 wt\% PVA) & $1841 \pm 15$ & $23 \pm 1$ \\
BS (1.4 wt\% PVA) & $1543 \pm 16$ & $35 \pm 1$ \\
CS (2.8 wt\% PVA) & $1511 \pm 2$ & $36 \pm 1$ \\
DS (4.0wt\% PVA) & $1443 \pm 19$ & $39 \pm 1$ \\
ES (5.6 wt\% PVA) & $1366 \pm 7$ & $41 \pm 1$ \\
\hline
\end{tabular}

TABLE 5. Bulk density and porosity of PVA-modified cement pastes with $\mathrm{w} / \mathrm{c}=0.35$.

very similar and there are no visible changes in their distribution (Figure 8).

The water absorption measurement clearly demonstrates the positive effect of the PVA content. Figure 9 clearly shows that the water absorption decreases almost linearly with the increasing PVA content. The BS samples exhibit about $20 \%$ less water absorption than the reference sample. In the case of the ES samples, the water absorption was reduced by almost $80 \%$.

The amount of water retained after 24 hours of natural drying is presented for all tested sets in Figure 10. The figure shows substantially less residual water held in all samples containing PVA; the BS samples retained about $10 \%$ less water than the reference samples, while the absorbed water was lost so rapidly in the case of the DS and ES samples that their weight after 24 hours corresponded to a completely dry state.

The results presented in Figures 11 and 12 demonstrate the influence of PVA on the dynamic Young's modulus and shear modulus of the cement pastes. 

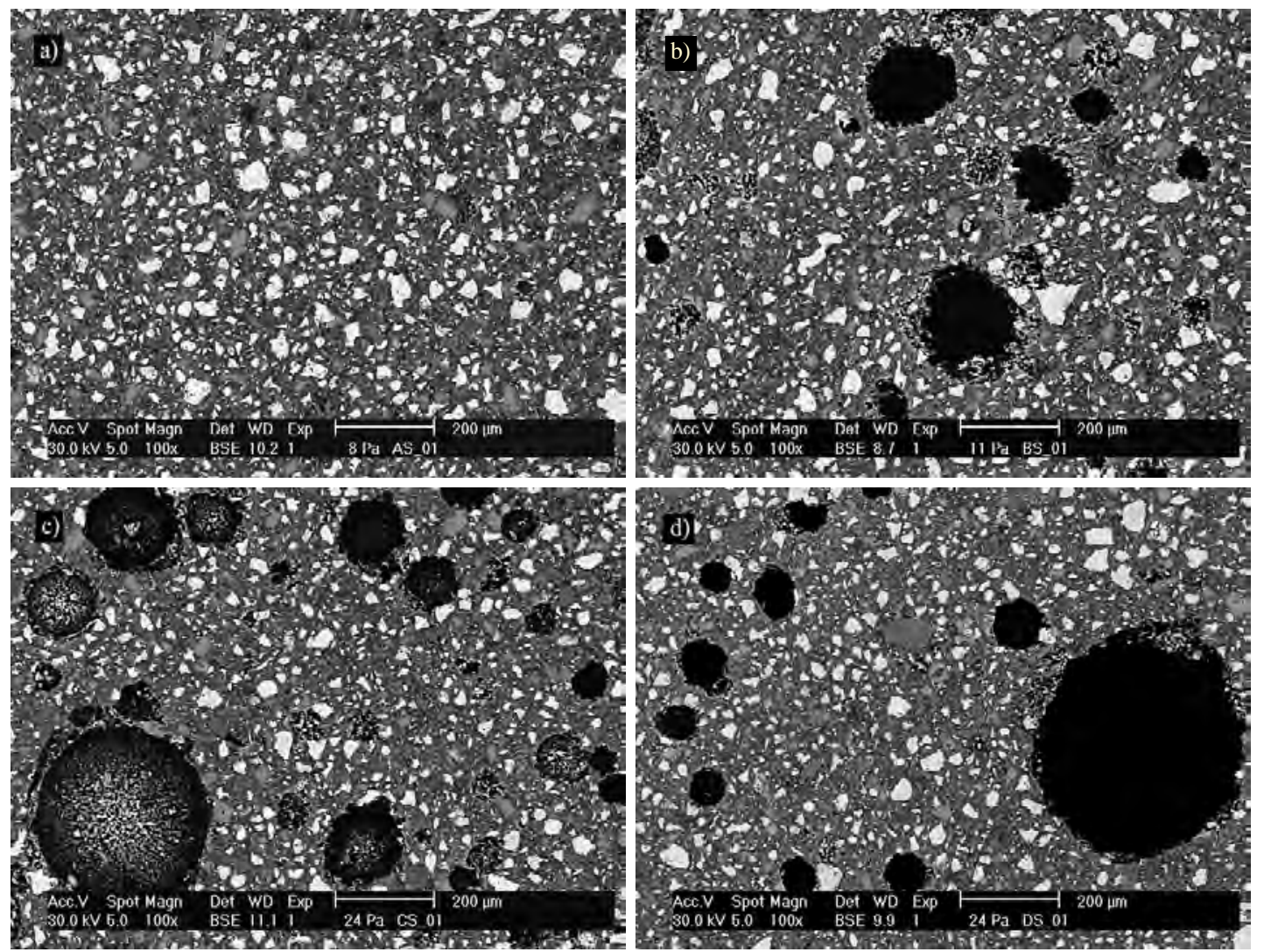

FIGURE 7. SEM images of the cement pastes with $\mathrm{w} / \mathrm{c}=0.35$ modified by PVA at $100 \times$ magnification: a) AS sample (0 wt\% PVA), b) BS sample (1.4 wt\% PVA), c) CS sample (2.8 wt\% PVA), d) DS sample (4.0 wt\% PVA).
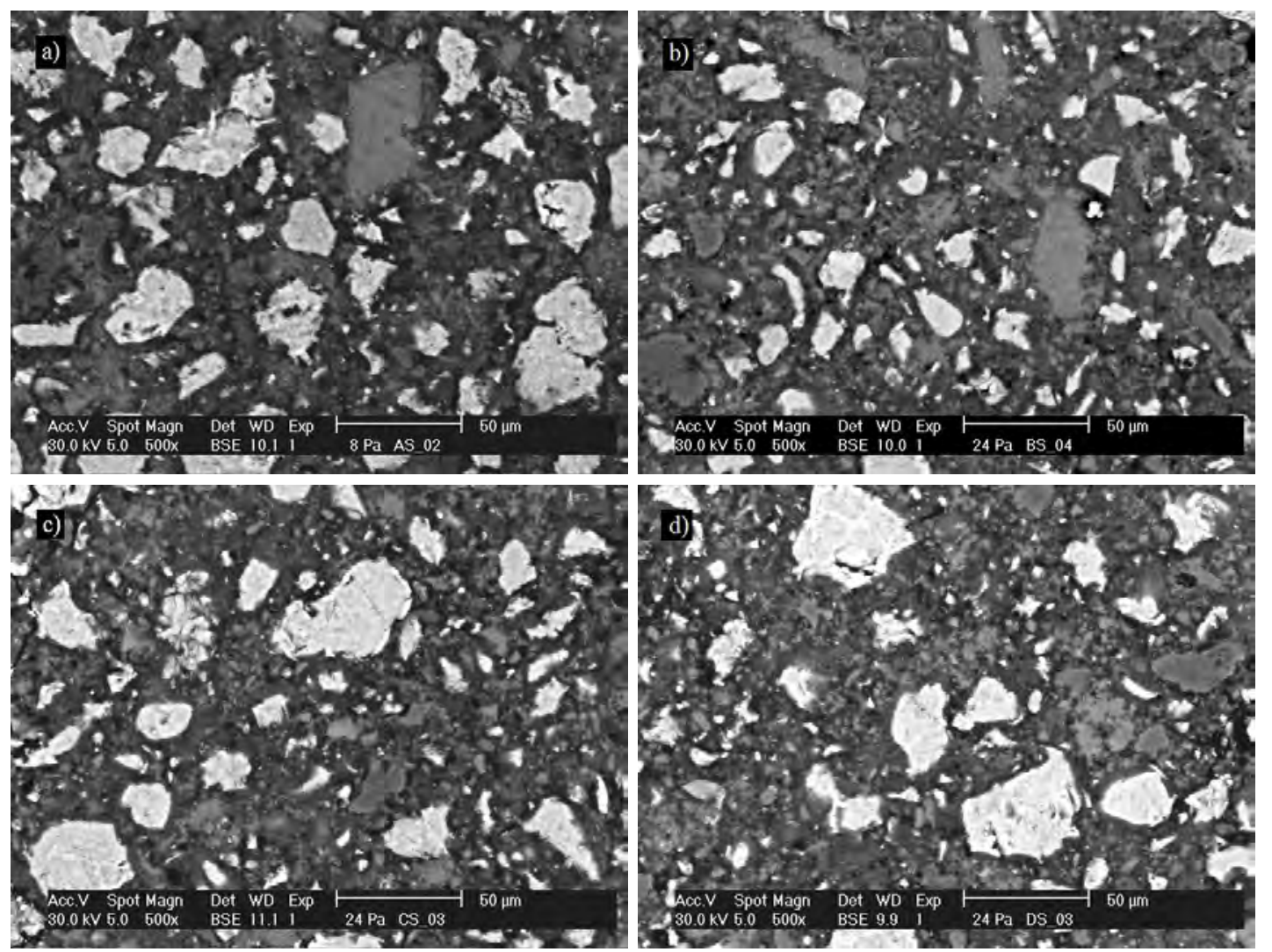

Figure 8. SEM images of the cement pastes with $w / c=0.35$ modified by PVA at $500 \times$ magnification: a) AS sample (0 wt\% PVA), b) BS sample (1.4 wt\% PVA), c) CS sample (2.8 wt\% PVA), d) DS sample (4.0 wt\% PVA). 


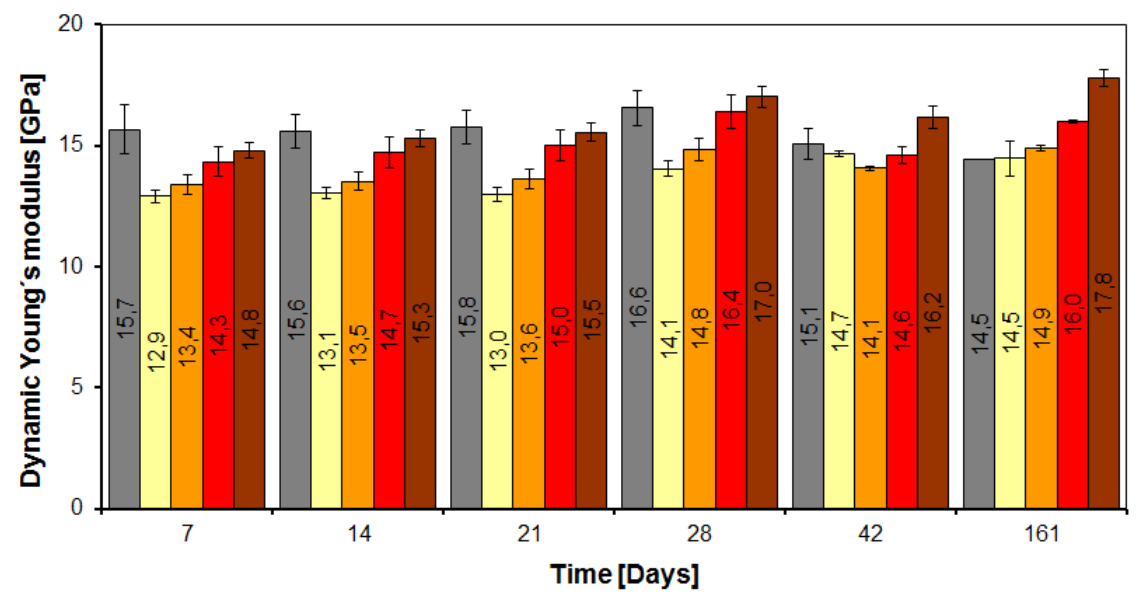

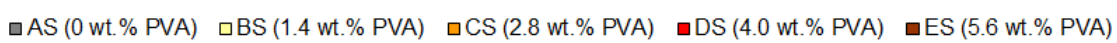

Figure 11. Development of the dynamic Young's modulus for PVA-modified cement pastes with w/c $=0.35$.

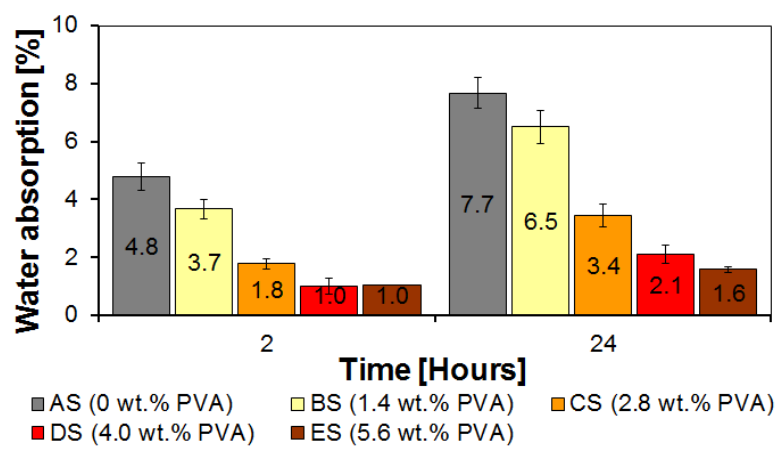

Figure 9. Water absorption (after 2 hours and 24 hours) of the PVA-modified cement pastes with $\mathrm{w} / \mathrm{c}=$ 0.35 .

In the early stages of hardening, both moduli of the PVA-modified pastes are lower than for the reference AS sample. Among the modified pastes, however, the more PVA is added, the higher the Young's modulus and the shear modulus. In the later hardening stages, the modified pastes attain higher elastic stiffness than the plain cement paste - after 161 days of curing the ES samples exhibited $23 \%$ higher dynamic Young's modulus values than the reference paste.

The flexural strength is proportional to the amount of PVA in the cement paste, as is clearly demonstrated in Figure 13 The ES samples rich in PVA reached about $45 \%$ higher flexural strength than the reference pure cement paste sample.

However, the compressive strength of PVA-enriched cement pastes is significantly reduced, and is almost constant with respect to the PVA content, see Figure 14. The drop is probably caused by the increase in porosity, which introduces local concentrations of deviatoric stress when the material is subjected to compression.

As indicated in the section on Experimental Methods, the values of the static Young's modulus are significantly lower than the values obtained from the

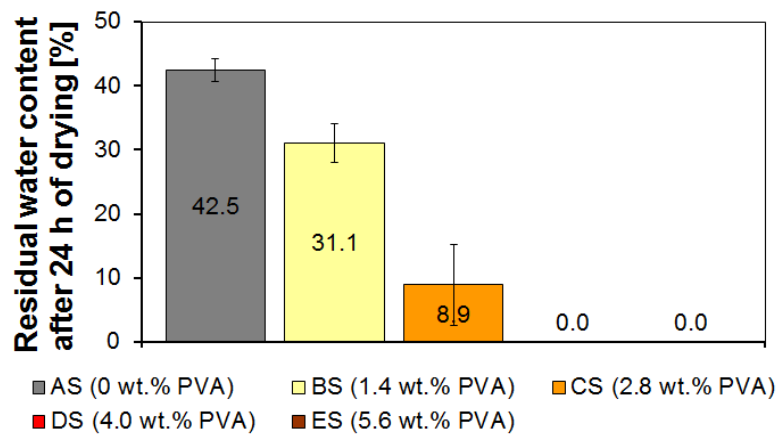

FiguRE 10. Residual water content in the PVAmodified cement pastes with $\mathrm{w} / \mathrm{c}=0.35$ after 24 hours of drying.

dynamic measurements. However, the trend of the development of elastic stiffness with respect to the PVA content is the same: there is an abrupt drop between the reference and the BS sample, followed by a small increase with the additional amount of PVA in the cement pastes.

\section{Discussion}

The reduced workability of PVA-rich cement pastes is caused by the high viscosity of the PVA solution. Our findings are completely different from those in the study by Kim et al. 11, who claim that workability improves with higher amounts of PVA in the fresh concrete. This observation may have been caused by the fact that the work of Kim et al. dealt with a mixture containing aggregates and having a higher water-to-cement ratio, equal to 0.5. On the basis of the workability testing results, the ES mixture was excluded from the bending and compressive strength tests, because it was almost impossible to create test samples and there would be a significant scatter of the results.

It is obvious from our experimental observations that the addition of PVA extended the setting and 


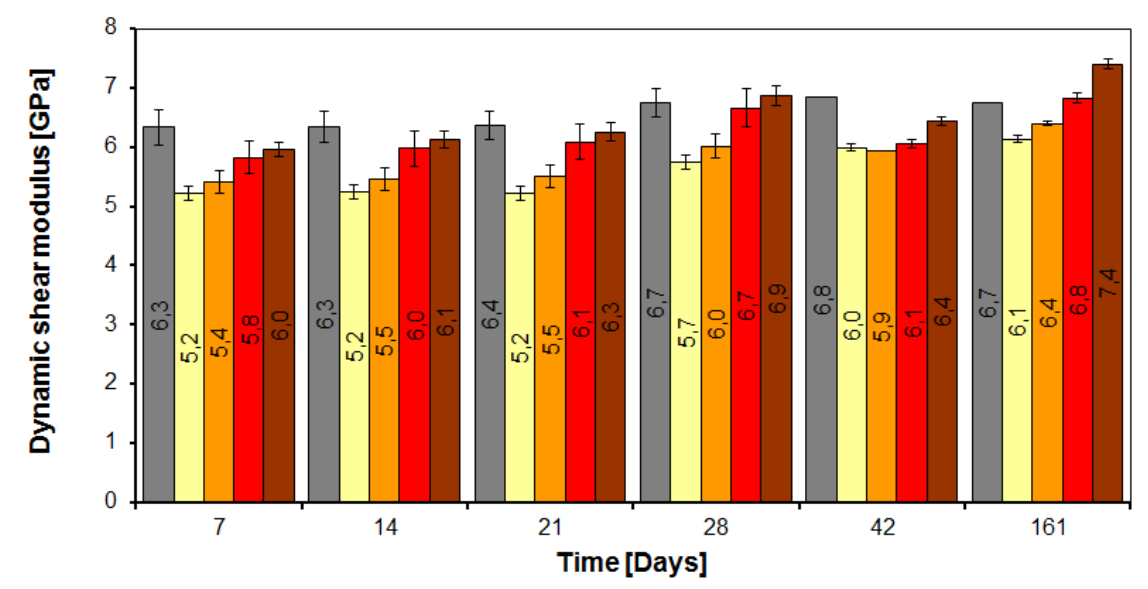

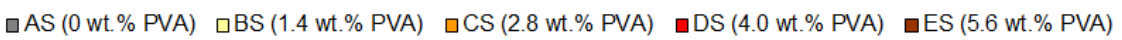

Figure 12. Development of the dynamic shear modulus for PVA-modified cement pastes with w/c $=0.35$.

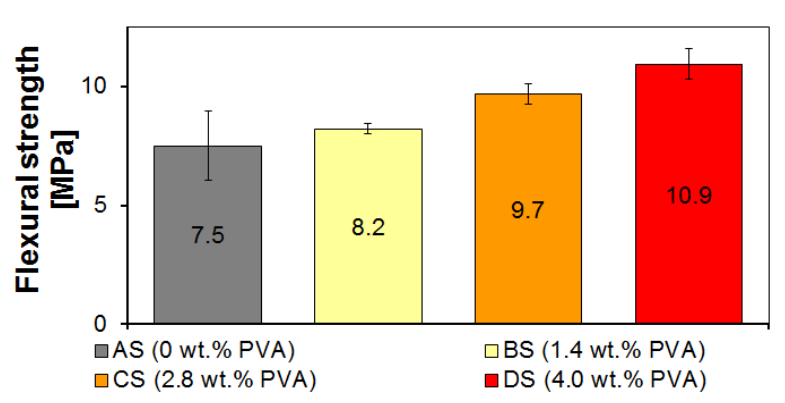

FiguRE 13. Dependence of flexural strength on the amount of PVA in cement pastes with $\mathrm{w} / \mathrm{c}=0.35$ after 28 days of curing.

hardening. This can be explained by the formation of a film that creates a barrier around unhydrated cement grains by preventing the absorption of water. This phenomenon would be similar to the effect of ettringite $(\mathrm{C} 3 \mathrm{~A})$ for clinker in ordinary Portland cement. The retardation of the hydration process in cement pastes containing moderately acidic PVA can also be caused by chemical incompatibility with the strongly acidic environment. Both mechanisms are described in the work of Knapen et al. 44, while Pique et al. [6] attribute the retardation to the PVA polarity. It should also be taken into consideration that affecting the hydration process can lead to limited formation of hydration products, and therefore to a reduction in the matrix density. As a consequence, the strength and the elastic modulus of the paste can also be reduced. Our measurements of the hydration heat development are in good agreement with the conclusions of Knapen et al. 4, Pique et al. 6] and Singh et al. 8]. However, the studies of other authors are not directly focused on the relationship between hardening time and an increased content of PVA. In those studies only one concentration of PVA or PVAA were used in the samples, which were different from ours, so only some values can be compared.

The decrease in the bulk density due to the increase



Figure 14. Dependence of compressive strength on the amount of PVA in cement pastes with $\mathrm{w} / \mathrm{c}=0.35$ after 28 days of curing.

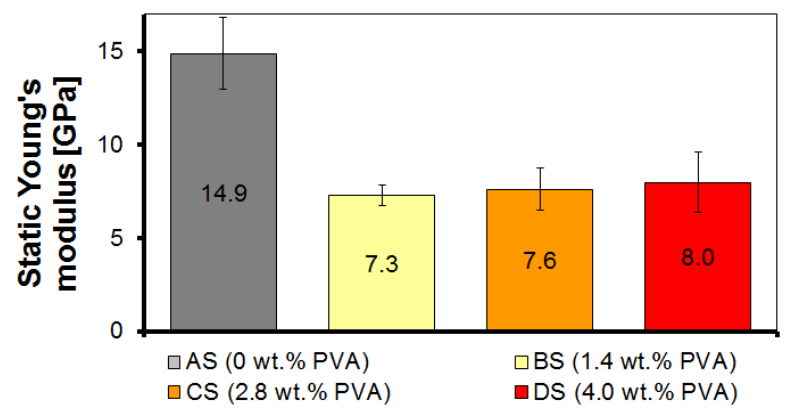

Figure 15. Dependence of the static Young's modulus on the amount of PVA in cement pastes with $\mathrm{w} / \mathrm{c}=$ 0.35 after 28 days of curing.

in porosity is also mentioned in the studies by Morlat et al. [7] and by Kim et al. [11]. Due to the different curing of the samples during hardening, and because the samples contained aggregates, the porosity and the bulk density of the samples could not be compared relevantly. However, the tendency of the bulk density and changes in porosity, confirming the introduction of pores with the addition of PVA, is similar as for the samples hardening in water. This phenomenon may be caused by the adhesion and the viscosity of the mixture, so that the air bubbles cannot escape from 
the fresh mortar. It is well known that porosity is the crucial factor influencing the mechanical properties of cement composites, water absorption and permeability 33 . It is therefore necessary to optimize the mixing and preparation process in order to reduce the porosity and obtain a material with the required properties [34, 35].

The microscopy images document the excessive formation of voids in samples with PVA and the fact that the shape and the concentration of voids corresponds to the technological porosity [1, 2]. However, the increased content of smaller pores (up to $30 \mu \mathrm{m}$ ) indicates that the pores could be a product of a chemical reaction. However, there was no substantial change in the amount and the morphology of individual phases detected in the BSE images, when compared with the reference pure cement paste [1, 2]. The BSE images provided by Kim et al. 11] indicate that there is a difference in the thickness of the transition zone between aggregates and the cement matrix in PVA-modified cement-based mortars. The absence of aggregates in our samples resulted in the absence of the interfacial transition zone, and also in crack formation, documented by Knapen et al. [4].

The measurement confirmed the assumption of a reduction in water absorption in the PVA-modified cement composites, mentioned in the study by Viswanath et al. [5]. This phenomenon can be attributed to the formation of a PVA coating both on the surface of the samples and on the surface of the pores. Reducing water absorption is a prerequisite for improvements in chemical and frost resistance. However, it is also necessary to mention that there was leaching of PVA from the submerged samples. This was proven by the settled PVA on the bottom of the container. The same findings were presented by Pique et al. 6], who also detected a strength improvement for submerged samples.

A decrease in the modulus of elasticity of the PVAmodified cement pastes with respect to the reference plain sample was also documented in the work of Morlat et al. [7], who concentrated on early age mortars. Unlike in our study, the modulus of elasticity of the samples decreased linearly with the amount of added PVA, while the trend in our measurements was rather constant or increasing. Figure 11 demonstrates an increase in the elastic stiffness modulus in the advanced stages of hardening (in the period between 28 and 161 days) for the CS and more PVA-rich samples. This phenomenon can be connected with strengthening of the cement bonds, resulting in higher strength in the case PVA-rich samples, despite their increased porosity. Such findings are supported by the dynamic shear modulus measurements, which indicate an increase in the elastic shear stiffness in the later stages of hardening with the addition of PVA. Morlat et al. concluded that the loss of stiffness of the cement mortar with the addition of PVA, reported in their study, was caused by increased porosity and low polymer stiffness values.
As was mentioned above, an increase in bending strength can be observed in the PVA-rich samples, despite the increase in porosity. This can be explained by bond strengthening, as suggested in the studies by Knapen et al. 3, 4, Morlat et al. [7] and Singh et al. 8]. Our results are in particular agreement with the measurements of Knapen et al. 3] and Pique et al. [6], and the minor deviations are attributed to a different water-to-cement ratio. The lower reduction in compressive strength of $4 \%$ PVA cement pastes in comparison with our results, documented in the paper by Pique et al. 6], is probably caused by different curing conditions and a higher water-to-cement ratio, and consequently by lower porosity. However, Pique et al. also came to the conclusion that PVA enrichment of cement pastes reduces their strength, as confirmed by Kim et al. [11, who eliminated excessive porosity by adding aggregates, and cured the mortar in a water bath. According to the study by Singh et al. 8, an increase in the compressive strength of PVA-enriched cement pastes by up to $30 \%$ can be achieved by the addition of gypsum and fly ash. The increase in PVA-rich samples (DS), in comparison with PVA-poor samples (BS) as demonstrated in Figure 14, confirms the hardening mechanism theory proposed by some authors [4, 7, 8].

\section{Conclusion}

The work presented here has focused on the influence of PVA additions on the microstructure and the mechanical properties of cement pastes. A comprehensive experimental study focused on the properties of PVA-modified cement pastes in the form of a fresh paste, during hardening, and after 28 days of age. On the basis of our results, we can conclude that:

- the PVA additions have a negative effect on the workability of the paste/mortar due to the high viscosity of the PVA solution,

- the hydration heat generation is reduced with increasing amounts of PVA, leading to an extended setting and hardening period,

- the PVA additions result in an increase of porosity (as documented by optical and electron microscopy images), causing a reduction in density, elastic and shear stiffness, and compressive strength, while increasing the bending strength,

- the water absorption is reduced by the presence of PVA, leading to enhanced chemical and frost resistance,

- the 4 wt\% PVA enriched samples appear to exhibit optimum mechanical properties while retaining satisfactory workability and a satisfactory amount of pores.

Future research will focus on improving the cement paste preparation technology and the curing conditions in order to achieve better workability and reduced porosity. A study investigating the influence of 
PVA content on frost resistance is in progress. Further attention will be paid to the modification of cementbased mortars and concrete.

Our results indicate that PVA-modified cementbased products and concrete could be efficiently utilized for constructing structural elements that are in contact with water, such as foundation piles, retaining walls, and water supply and sewage structures. The lower hydration heat generation caused by adding the PVA solution into fresh concrete could be also exploited to eliminate the expensive cooling systems needed for the construction of large-scale structural elements, such as bridge piers.

\section{ACKNOWLEDGEMENTS}

Financial support from the Faculty of Civil Engineering, Czech Technical University in Prague (SGS projects No. SGS14/122/OHK1/2T/11 and SGS14/029/OHK1/1T/11) and from Czech Science Foundation (GAČR) project No. P108/12/0891 are gratefully acknowledged. The authors also thank the Center for Nanotechnology in Civil Engineering at the Faculty of Civil Engineering, CTU in Prague, and the Joint Laboratory of Polymer Nanofiber Technologies of the Institute of Physics, Academy of Science of the Czech Republic, and the Faculty of Civil Engineering, CTU in Prague.

\section{REFERENCES}

[1] Bensted, J. and Barnes, P. Structure and Performance of Cements. London, Spon Press, 2002, pp. 1-108, ISBN 0-203-47778-2.

[2] Ohama, Y. Handbook of polymer-modified Concrete and Mortars. New Jersey, Noyes Publications, 1995, pp. 1-222, ISBN 0-8155-1358-5.

[3] Knapen, E. and Gemert, D. V. Effect of underwater storage on bridge formation by water-soluble polymers in cement mortars. Construction and Buildings Materials, vol. 23, 2009, p. 3420-3425. DOI:10.1016/j.conbuildmat.2009.06.007.

[4] Knapen, E. and Gemert, D.V. Cement hydration and microstructure formation in the presence of watersoluble polymers. Cement and Concrete Research, vol. 39, 2009, p. 6-13. DOI:10.1016/j.cemconres.2008.10.003.

[5] Viswanath, P., Thachil, E.T. Properties of polyvinyl alcohol cement pastes. Materials and Structures, vol. 41, 2008, p. 123-130. DOI:10.1617/s11527-007-9224-2.

[6] Pique, T. M. and Vazquez, A. Control of hydration rate of polymer modified cements by the addition of organically modified montmorillonites. Cement and Concrete Composites, vol. 37, p. 54-60, 2013. DOI:10.1016/j.cemconcomp.2012.12.006.

[7] Morlat, R., Orange, G., Bomal, Y., Godard, P. Reinforcement of hydrated Portland cement with high molecular mass water-soluble polymers. Journal of Materials Science, vol. 42, 2007, p. 4858-4869. DOI:10.1007/s1085š-006-0645-z.

[8] Sing, N. B., Rai, S. Effect of polyvinyl alcohol on the hydration of cement with rice husk ash. Cement and Concrete Research, vol. 31, 2001, p. 239-243. DOI:10.1016/S0008-8846(00)00475-0.
[9] Yongjia, H. E. et al. Effect of Water Soluble PVA on the Microstructure Characteristics of C-S-H Formed in $\mathrm{Na} 2 \mathrm{SiO} 3 \mathrm{Ca}(\mathrm{NO} 3) 2$ Solution System. Journal of Wuhan University of Technology - Mater. Sci. Ed., vol. 26, No. 3, 2011, p. 552-555. DOI:10.1007/s11595-011-0266-5.

[10] Kim, J.-H. and Robertson, R. E. Effects of Polyvinyl Alcohol on Aggregate-Paste Bond Strength and the Interfacial Transmission Zone. Advanced Cement Based Materials, vol. 8, 1998, p. 66-76, DOI:10.1016/S1065-7355(98)00009-1.

[11] Kim, J.-H., Robertson, R. E., Naaman, A. E. Structure and properties of poly(vinyl-alcohol)-modified mortar and concrete. Cement and Concrete Research, vol. 29, p. 407-415, 1999. DOI:10.1016/S0008-8846(98)00246-4.

[12] Mojumdar, S. C., Raki, L. Preparation and properties of calcium silicate hydrate-poly(vinyl alcohol) nanocomposite materials. Journal of Thermal Analysis and Calorimetry, vol. 82, p. 89-95, 2005. DOI:10.1007/s10973-005-6837-y.

[13] Kou, S.-C., et al. Structure Properties of concrete prepared with PVA-impregnated recycled concrete aggregates. Cement and Concrete Composites, vol. 32, p. 649-654, 2010. DOI:10.1016/j.cemconcomp.2010.05.003.

[14] Shaikh, F. U. A., Hirozo, M. Strain hardening behavior of lightweight hybrid polyvinyl alcohol (PVA) fiber reinforced cement composites. Materials and Structures, vol. 44, p. 1179-1191, 2011. DOI:101.1617/s11527-010-9691-8.

[15] Shilang, X., Shuling, G. Fracture and Tensile Properties of PVA Fiber Reinforced Cementitious Composites. Journal of Wuhan University of Technology-Mater. Sci. Ed., vol. 23, No. 1, p. 7-11, 2008. DOI:10.1007/s11595-006-1007-z.

[16] Noushini, A., et al. Effect of PVA fiber on dynamic and material properties of fiber reinforced concrete. Construction and Building Materials, vol. 49, p. 374-383, 2013. DOI:10.1016/j.conbuildmat.2013.08.035

[17] Shen, B. et al. Functionally-graded fiber-reinforced cement composite: Processing, microstructure, and properties. Cement and Concrete Composites, vol. 30, p. 663-673, 2008. DOI:10.1016/j.cemconcomp.2008.02.002.

[18] Lhoneux, B. et al. Durability study of PVA fibers in fiber-cement products. Proceedings of the Vth International Symposium, Concrete for a Sustainable Agriculture, p. 275-284, 2012.

[19] Mechtcherine, V. et al. Coupled strain rate and temperature effects on the tensile behavior of strain-hardening cement-based composites (SHCC) with PVA fibers. Cement and Concrete Research, vol. 42, p. 1417-1427, 2012. DOI:10.1016/j.cemconres.2012.08.011.

[20] EN 12350-5: 2009. Testing fresh concrete. Flow table test

[21] EN 196-3:2005+A1:2008. Methods of testing cement - Part 3: Determination of setting times and soundness.

[22] Demo, P. et al. Physical and Chemical Aspects of the Nucleation of Cement-Based Materials. Acta Polytechnica, Vol. 5, No. 6/2012. 
[23] Ficker, T., Martišek, D., Jennings, H. M. Surface Roughness and Porosity of Hydrated Cement Paste. Acta Polytechnica, Vol. 51, No. 3/2011.

[24] Ficker, T. Fracture Surface of Porous Materials. Acta Polytechnica, Vol. 51, No. 3/2011.

[25] Šmilauer, V., Hlaváček, P., Padevět, P.

Micromechanical Analysis of Cement Paste with Carbon Nanotubes. Acta Polytechnica, Vol. 52, No. 6/2012.

[26] Brüel \& Kjær Sound \& Vibration Measurement A/S. http://www.bksv.com [2015-02-01].

[27] ASTM E1876-01 (2006). Standard Test Method for Dynamic Young's Modulus, Shear Modulus, and Poisson's Ratio by Impulse Excitation of Vibration.

[28] TA Instruments. http://www.tainstruments.com [2015-02-01].

[29] ČSN 73 1372: 2012. Nedestruktivní zkoušení betonu Rezonanční metoda zkoušení betonu.
[30] EN 12390-5: 2009. Testing hardened concrete Part 5: Flexural strength of test specimens.

[31] EN 12390-3: 2009. Testing hardened concrete Part 3: Compressive strength of test specimens.

[32] ISO 1920-10: 2010. Testing of concrete - Part 10: Determination of static modulus of elasticity in compression.

[33] Ficker, T. Surface Morphology of Porous Cementitious Materials Subjected to Fast Dynamic Fractures. Acta Polytechnica, Vol. 51, No. 5/2011.

[34] Vodak, F., et al. Effect of gamma-irradiation on strength of concrete for nuclear-safety structures. Cement and Concrete Research, vol. 35, p. 1447-1451, 2005. DOI:10.1016/j.cemconres.2004.10.016

[35] Demo, P., et al. Analytical approach to time lag in binary nucleation. Physical Review E, vol. 59, p. 5124-5127, 1999. DOI:10.1103/PhysRevE.59.5124 